\title{
Veno-arterial extracorporeal membrane oxygenation for electrical injury induced cardiogenic shock support: a case report
}

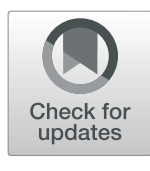

Tamer Jamal ${ }^{1,2}$, Amjad Shalabi ${ }^{1,2}$, Liza Grosman-Rimon ${ }^{1}$ (D), Diab Ghanim ${ }^{1,3}$, Offer Amir ${ }^{1,3}$ and Erez Kachel ${ }^{1,2,3^{*}}$

\begin{abstract}
Background: High voltage electrical injury (HVEI) of more than $1000 \mathrm{~V}$ is a potentially devastating form of a multisystem injury associated with high morbidity and mortality.

We present the first case of veno-arterial extracorporeal membrane oxygenation (VA-ECMO) as a life saving device for treating a patient with severe cardiogenic shock after a high voltage electrical injury.
\end{abstract}

Case presentation: A 26-year-old male sustained HVEI while working with a concrete mixer pump that came in contact with a high voltage cable of 10,000 V. He was immediately disconnected from the mixer pump, underwent cardiopulmonary resuscitation and was transported to the nearest medical centre with severe cardiogenic shock with an ejection fraction (EF) of $<10 \%$.

Upon arrival, he was in critical condition, sedated and mechanically ventilated, haemodynamically unstable and supported by intravenous (IV) inotropes after a few events of ventricular fibrillation, with an electrical entry point on the left hand and an exit point located on his right leg. $\mathrm{Blood} \mathrm{pH}$ was $6.8, \mathrm{PCO}_{2} 53 \mathrm{mmHg}, \mathrm{PaO}_{2}$ of $57 \mathrm{mmHg}$, lactate $8 \mathrm{mmol} / \mathrm{L}$, and Troponin 38,000 $\mathrm{ng} / \mathrm{dl}$. The EF was $10 \%$ with global severe left ventricular dysfunction. During cardiopulmonary resuscitation (CPR), including cardiac massage and few electrical shocks, he was immediately connected to the VA-ECMO via open right femoral approach with distal arterial leg perfusion.

He was treated with IV broad spectrum antibiotics, and high volume fluids to prevent rhabdomyolysis-induced acute kidney injury, total parenteral nutrition, topical silver sulfadiazine cream, and Granuflex for severe electrical burns. He was gradually weaned from inotropes over the next 3 days, during which his clinical condition and bloodwork improved tremendously. His EF gradually increased to $50 \%$ and he was weaned from the VA-ECMO, and underwent decannulation $86 \mathrm{~h}$ after initialization. He was discharged on day 27 without any sequelae.

Conclusion: The VA-ECMO treatment can be a lifesaving device for treating severe cardiogenic shock caused by high voltage electrical injury, and should be considered while treating these "high-mortality risk" patients.

Keywords: Extracorporeal membrane oxygenation, Cardiogenic shock support, Electrical injury: case report

\footnotetext{
* Correspondence: erezk@bezeqint.net; Erez.Kachel@sheba.health.gov.il

${ }^{1}$ Cardiac Surgery Department, B Padeh Medical Center, Poriya, Israel

${ }^{2}$ Department of Cardiac Surgery, Sheba Medical Centre, 5265601 Tel Hashomer, Israel

Full list of author information is available at the end of the article
}

(c) The Author(s). 2020 Open Access This article is licensed under a Creative Commons Attribution 4.0 International License, which permits use, sharing, adaptation, distribution and reproduction in any medium or format, as long as you give appropriate credit to the original author(s) and the source, provide a link to the Creative Commons licence, and indicate if changes were made. The images or other third party material in this article are included in the article's Creative Commons licence, unless indicated otherwise in a credit line to the material. If material is not included in the article's Creative Commons licence and your intended use is not permitted by statutory regulation or exceeds the permitted use, you will need to obtain permission directly from the copyright holder. To view a copy of this licence, visit http://creativecommons.org/licenses/by/4.0/ The Creative Commons Public Domain Dedication waiver (http://creativecommons.org/publicdomain/zero/1.0/) applies to the data made available in this article, unless otherwise stated in a credit line to the data. 


\section{Introduction}

Electrical injury is an infrequent but potentially devastating form of multisystem injury associated with high morbidity and mortality [1]. Despite significant improvement in injury prevention and implementation of safety protocols at work places, electrical injury accounts for more than 500 deaths per year in the United States with a mortality rate of 10 $30 \%$ [2]. Electrical injuries are divided into low-voltage electric power injuries (less than $1000 \mathrm{~V}$ ) and high-voltage electric power injuries (more than $1000 \mathrm{~V}$ ) [2].

Cardiac injuries induced by electrical shock can be divided into arrhythmias, conduction abnormalities, and myocardial damage - whether there is direct electricity exposure or secondary myocardial injury after hypotension, or coronary arteries spasm [3-5]. Early treatment of cardiogenic shock with appropriate circulation support may be vital with veno-arterial extracorporeal membrane oxygenation (VA-ECMO), as one of the therapeutic armamentarium in refractory cardiogenic shock [6].

Although veno-venous- ECMO (VV-ECMO) was used previously to support lung failure after electrical injury [7], the VA-ECMO to support cardiogenic shock secondary to high voltage electrical injury, has not yet been described. We present the first case demonstrating the role of VAECMO in resuscitating electrically injured patients.

\section{Case presentation}

A 26-year-old man sustained a high voltage electrical injury $(>1000 \mathrm{~V})$ while he was working with a concrete mixer pump that came in contact with high voltage cable of $10,000 \mathrm{~V}$. The patient was disconnected from the tube immediately due to the jolt, lost consciousness and a cardiac massage was launched within $3 \mathrm{~min}$ by witnesses. Then, advanced life support was supplied by paramedics as ventricular fibrillation was detected. He was referred to the nearby emergency room (ER) of a secondary hospital with cardiogenic shock, being chest compressed by a LUCAS machine. In the ER, advanced cardiovascular life support continued for more than $30 \mathrm{~min}$.

After resuscitation, the patient was still supported with IV Noradrenaline. He was then referred to our institute. A physical exam conducted upon his admission showed an unconscious ventilated patient with reactive dilated pupils, tachycardia and a normal bilateral vesicular breathing sound. Electrical entry point was detected on the left hand; exit points were on the feet, bilaterally. ECGs showed sinus tachycardia with PVCs. The arterial blood test showed: $\mathrm{PH}$ 6.8, $\mathrm{PCO}_{2} 53 \mathrm{mmHG}, \mathrm{PaO}_{2} 57 \mathrm{mmHg}$, lactate $8 \mathrm{mmol} / \mathrm{l}$, and troponin 38,000 ng/dl. The ECG showed an estimated ejection fraction (EF) of $10 \%$, with global dysfunction and a reserved valves' function. After the heart team consulted, the patient was then connected to the VA-ECMO within 30 min of his admission, via a right femoral approach with distal perfusion.

\section{Management}

VA-ECMO support was supplied for $86 \mathrm{~h}$ (3.6 days).

During this period, multiple signs and blood tests were performed, among them those related to VA-ECMO (Tables 1 and 2).

Other points of care included: suspicion of aspiration on the day of admission; he was treated by antibiotics. Diagnosis of right pleural effusion which was drained by a chest tube. Fluid administration to prevent rhabdomyolysis induced acute kidney injury. Total parenteral nutrition for visceral electrical injury, which resulted in decreased enteral absorption. Burn wounds were treated locally by utilizing silver sulfadiazine cream (Silverol) and Granuflex dressings.

\section{Outcomes}

Within the first day, the patient had been weaned from noradrenaline. The lactate level declined gradually down to $0.6 \mathrm{mmol} / \mathrm{L}$. A follow up echocardiography on the third day showed improvement in cardiac function, with an $\mathrm{EF}=50 \%$ and normal right ventricular function. After $86 \mathrm{~h}$ of mechanical support, the patient underwent decannulation from VA-ECMO successfully.

The weaning process was gradual, starting with decreasing the VA-ECMO to $1 \mathrm{l} / \mathrm{min}$ for $24 \mathrm{~h}$ before decannulation, during this period a trans oesophageal echocardiography was completed, making sure biventricular functions were within the normal range and there was no ventricular dilatation. Chest X-rays showed no new opacities or indications of ARDS. Other parameters that we followed within this period were Central Venous Pressure (CVP), PH, lactate and target organ blood test, to endure normal function.

On the day of decannulation, we stopped heparin, once ACT was less than 160, we conducted decannulation successfully. A transthoracic echocardiography conducted 1 day after the decannulation showed normal biventricular and valves function.

Table 1 Patient's Clinical Outcomes

\begin{tabular}{ll}
\hline Clinical Outcomes & \\
\hline Flow & 4 L/MIN \\
Round per minute & 3360 \\
Pre-membranous pressure & 200 \\
Post-membranous pressure & 170 \\
ECMO FIO2 & $60 \%$ \\
ACT & $180-220$ \\
BRAIN SAT & $70 \%$ \\
PUPIL EXAM & ROUND, REACTIVE TO LIGHT \\
LOWER LIMB SAT & RIGHT 90\%, LEFT 70\% \\
\hline
\end{tabular}


Table 2 Patient's Biomarker Levels Before, During cannulationafter ECMO

\begin{tabular}{lllll}
\hline & Day 1 of admission & After 2 days on ECMO & 1 day after ECMO decannulation & ARDS and referral day \\
\hline WBC $($ uL/1000) & 36.6 & 18 & 19 & 25 \\
HEMOGLOBIN $(\mathrm{g} / \mathrm{dl})$ & 18 & 10 & 9.9 & 9.6 \\
PLATELETS $(\mathrm{uL} / 1000)$ & 343 & 167 & 150 & 950 \\
CREATININE $(\mathrm{mg} / \mathrm{dl})$ & 1.5 & 1.1 & 1 & 2.5 \\
LDH $(\mathrm{U} / \mathrm{L})$ & 1315 & 1650 & 950 & 950 \\
CPK $(\mathrm{U} / \mathrm{L})$ & 8250 & 18000 & 10000 & 2800 \\
AST $(\mathrm{U} / \mathrm{L})$ & 1200 & 450 & 450 & 270 \\
ALT $(\mathrm{U} / \mathrm{L})$ & 425 & 150 & 150 & 130 \\
LACTATE $(\mathrm{mmol} / \mathrm{l})$ & 8 & 0.6 & 1.4 & 1.9 \\
PH & 6.8 & 7.45 & 7.4 & 7.32 \\
\hline
\end{tabular}

Acute respiratory distress syndrome (ARDS) was diagnosed on the 6th day of hospitalization and was treated accordingly Fig. 1.

On the seventh day, the patient was referred to the ARDS specialized department in a primary medical centre, being anesthetised and ventilated for continuous treatment. There, he was hospitalized for almost a month. During this period he passed tracheostomy and then was gradual weaned and underwent respiratory physiotherapy up until discharge. No plastic surgery was done and the burns were treated topically. Two months after the accident, he was discharged and moved to rehabilitation centre.

His chest X-rays at the discharge from the ARDS specialized department is shown in Fig. 2. His blood tests at discharge were normal, especially renal functions - creatinine $0.7 \mathrm{mg} / \mathrm{dl}$.

A follow-up transthoracic echocardiography showed - left ventricle with normal global systolic function $(E F=65 \%)$ with no regional wall abnormality. The right ventricle was found to be normal size and properly functioning. The aortic valve was normally functioning, as were the mitral, tricuspid and pulmonary valve, with minimal regurgitation.

\section{Discussion}

The patient presented with high voltage electrical burn induced cardiogenic shock, with multi-organ failure; instant transthoracic echocardiography indicated EF of $10 \%$,so he was immediately supported by the VA-ECMO.

To our knowledge, veno-venous- ECMO (VV-ECMO) was used to support lung failure after electrical injury [7]. However, this is the first report of cardiogenic shock requiring VA-ECMO support, secondary to high voltage electrical injury. For note, VA-ECMO treatments may not be effective in all high voltage electrical injury cases.

The rationales for VA-ECMO connection in our case were the young age, low cardiac output in the setting of
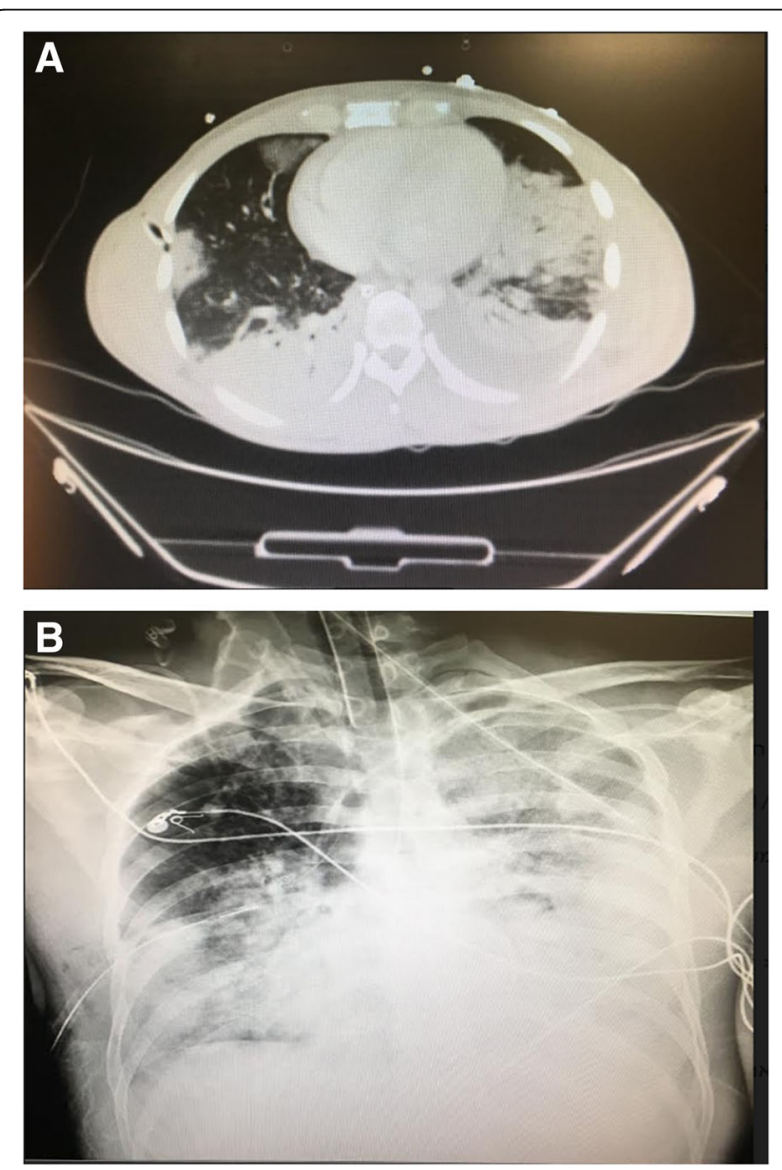

Fig. 1 a Computed tomogram of the patient with ARDS, demonstrating bilateral dependent consolidation, a large consolidation in the LUL, and small peripheral patchy alveolar infiltrate on the right. $\mathbf{b}$ A chest radiograph of the patient on the 6th day of hospitalization, showing ARDS with bilateral infiltrates and bilateral heterogeneous consolidations, more on the left side 


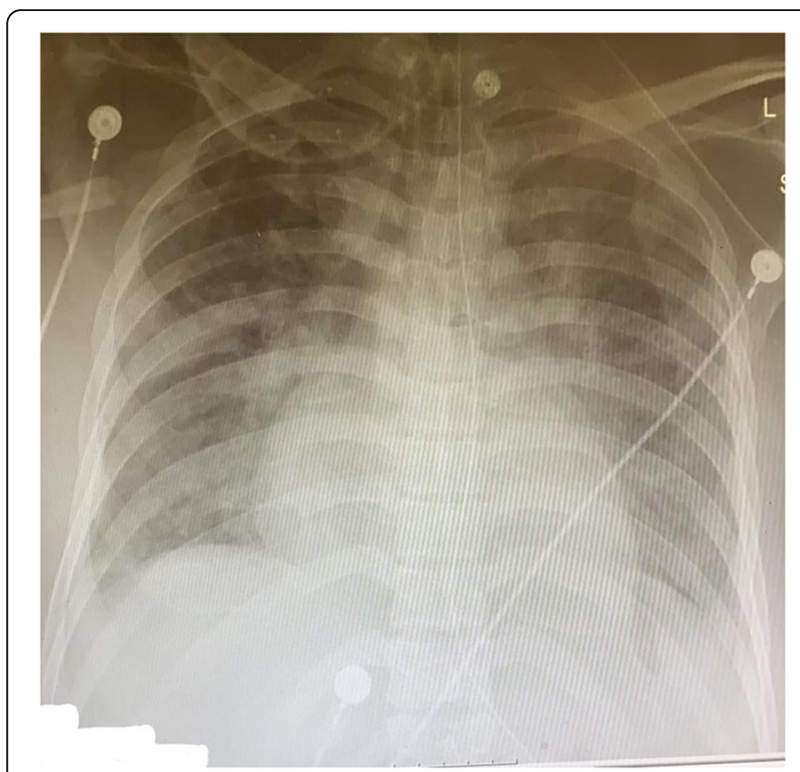

Fig. 2 Chest $x$-ray at discharge from the ARDS specialized department, showing no infiltrates or consolidation

multiple organ dysfunction, and the risk of additional arrhythmias that might deteriorate cardiac function further and lead to dreadful results. So, we believed that the circulatory support via VA-ECMO will supply better perfusion, even in the presence of serious arrhythmias, for the target organs and improving their function. Moreover, we took into consideration that VA-ECMO can be used as a bridge for surgical salvage (assistant device implantation or cardiac transplant) in the case of persistent heart failure.

Cardiac injury after an electrical jolt may happen due to arrhythmias - ventricular fibrillation can occur with low-voltage alternating current, whereas asystole is more common with direct current or high-voltage alternating current [3]. The mechanism behind electrically induced cardiac arrhythmias is not entirely clear but may involve patchy areas of myocardial necrosis, which serve as arrhythmogenic foci, as well as increased cardiac sodiumpotassium pump activity [4].

Moreover, electrical exposure may cause direct myocardial tissue damage through transcardiac passage of the electric current or indirect damage through ischemic injury, precipitated by arrhythmia-induced hypotension or a coronary artery spasm [3].

Electrical energy is capable of damaging most organs, depending on current intensity and pathway, which could lead to a life-threatening clinical state [5]. Organ damage by electrical energy includes superficial and deep burn wounds, rhabdomyolysis/ compartment syndrome, acute renal failure due to myoglobinurea or ischemia as well as respiratory arrest, as a result of either direct injury to the respiratory control centre, causing cessation of respiration, or to suffocation secondary to tetanic contractions of the respiratory muscles [5].

The recovery of these organs' functions is challenging, especially in cases of a failing heart. We think that in such electrically injured moribund patients, VA-ECMO can be an instant salvage for mechanical circulatory support, and can help in restoring organ function, including the heart. In our case we used VA-ECMO to stabilize the patient instantly and to supply effective support for the organs until the heart regained its own normal function.

\section{Conclusion}

VA-ECMO can be a crucial lifesaving device for treating severe cardiogenic shock caused by electrical injury, especially in high voltage electrical injury, and should be considered while treating these high-mortality risk patients.

\section{Abbreviations}

HVEl: High voltage electrical injury; EF: Ejection fraction; VA-ECMO: Venoarterial extracorporeal membrane oxygenation; IV: Intravenous; CPR: Cardiopulmonary resuscitation; ER: Emergency room; W-ECMO: Venovenous-extracorporeal membrane oxygenation; ARDS: Acute respiratory distress syndrome

\section{Acknowledgements}

Not applicable.

\section{Authors' contributions}

All authors contributed to the manuscript and met the criteria for authorship. The author(s) read and approved the final manuscript.

\section{Funding}

No funding was received.

\section{Availability of data and materials}

Please contact the authors for data requests.

Ethics approval and consent to participate

This study was approved by the ethics committee of Poriya Medical Center

\section{Consent for publication}

A consent was obtained from the patient to publish the case following the patient's recovery.

\section{Competing interests}

The authors declare that they have no competing interests.

\section{Author details}

${ }^{1}$ Cardiac Surgery Department, B Padeh Medical Center, Poriya, Israel. ${ }^{2}$ Department of Cardiac Surgery, Sheba Medical Centre, 5265601 Tel Hashomer, Israel. ${ }^{3}$ The Azrieli Faculty of Medicine in the Galilee, Bar-Ilan University, Safed, Israel.

Received: 18 February 2020 Accepted: 7 June 2020

Published online: 17 June 2020

\section{References}

1. Shih JG, Shahrokhi S, Jeschke MG. Review of adult electrical burn injury outcomes worldwide: an analysis of low-voltage vs high-voltage electrical injury. J Burn Care Res. 2017:38(1):e293-8.

2. Daskal Y, Beicker A, Dudkiewicz M, Kessel B. High voltage electric injury: mechanism of injury, clinical features and initial evaluation. Harefuah. 2019; 158(1):65-9.

3. Spies C, Trohman RG. Narrative review: electrocution and life-threatening electrical injuries. Ann Intern Med. 2006;145(7):531-7. 
4. Jensen PJ, Thomsen PE, Bagger JP, Norgaard A, Baandrup U. Electrical injury causing ventricular arrhythmias. Br Heart J. 1987:57(3):279-83.

5. Waldmann V, Narayanan K, Combes N, Jost D, Jouven X, Marijon E. Electrical cardiac injuries: current concepts and management. Eur Heart J. 2018;39(16): 1459-65.

6. Vahdatpour C, Collins D, Goldberg S. Cardiogenic shock. J Am Heart Assoc. 2019;8(8):e011991.

7. Chou NK, Chen YS, Ko WJ, et al. Application of extracorporeal membrane oxygenation in adult burn patients. Artif Organs. 2001;25(8):622-6.

\section{Publisher's Note}

Springer Nature remains neutral with regard to jurisdictional claims in published maps and institutional affiliations.

Ready to submit your research? Choose BMC and benefit from:

- fast, convenient online submission

- thorough peer review by experienced researchers in your field

- rapid publication on acceptance

- support for research data, including large and complex data types

- gold Open Access which fosters wider collaboration and increased citations

- maximum visibility for your research: over $100 \mathrm{M}$ website views per year

At $\mathrm{BMC}$, research is always in progress.

Learn more biomedcentral.com/submissions 